\title{
16. Międzynarodowa Akademia Dermatologii i Alergologii
}

\author{
Gdynia, 7-9 lutego 2020 r.
}

Dermatol Rev/Przegl Dermatol 2020, 107, 84-88

Sekcja Dermatologiczna Polskiego Towarzystwa Alergologicznego, Katedra i Klinika Dermatologii, Wenerologii i Alergologii Gdańskiego Uniwersytetu Medycznego (GUMed) oraz Oddział Morski Polskiego Towarzystwa Dermatologicznego (PTD) już po raz szesnasty byli organizatorami zimowego spotkania alergologów i dermatologów. Tegoroczna konferencja odbyła się w dniach 7-9 lutego, już po raz drugi w Gdyni, gdzie najprawdopodobniej "zakotwiczy” na stałe. Jak co roku to wydarzenie naukowe miało charakter interdyscyplinarny i było skierowane do lekarzy reprezentujących różne specjalności, którzy pragną uaktualnić i poszerzyć wiedzę w zakresie chorób alergicznych oraz najczęściej rozpoznawanych dermatoz.

Patronat honorowy nad 16. Międzynarodową Akademią Dermatologii i Alergologii (16. ADA) objęli Minister Zdrowia, a także JM Rektor Gdańskiego Uniwersytetu Medycznego, Prezes Polskiego Towarzystwa Dermatologicznego, Prezydent Polskiego Towarzystwa Alergologicznego, Marszałek Województwa Pomorskiego i Prezydent Gdyni.

Oficjalne otwarcie konferencji poprzedziło 10 interaktywnych warsztatów szkoleniowych z zakresu diagnostyki alergologicznej, pokrzywki, dermatourologii, dermoskopii, psychodermatologii, dermatologii estetycznej, leczenia ran przewlekłych, terapii biologicznej łuszczycy, leków recepturowych (ryc. 1) oraz modelowania twarzy. Podobnie jak w latach poprzednich

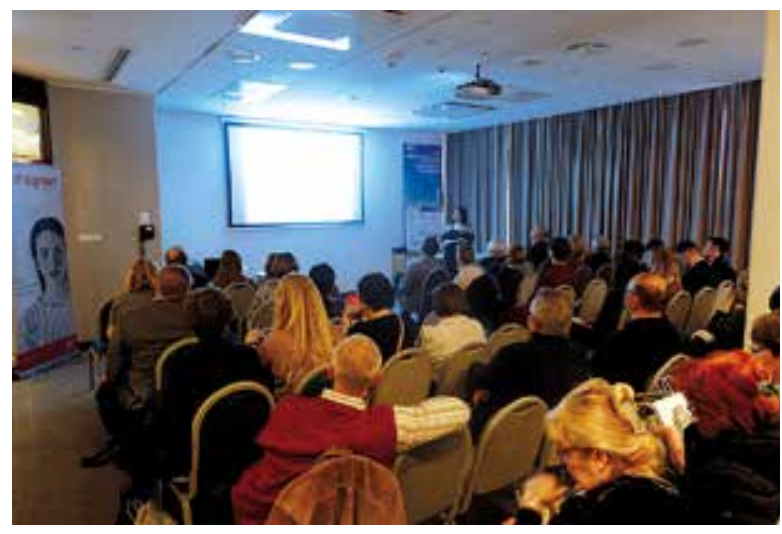

Rycina I. Profesor M. Sznitowska prowadzi warsztaty recepturowe sale warsztatowe okazały się zbyt małe, aby pomieścić wszystkich chętnych uczestników.

Bezpośrednio przed inauguracją odbyła się specjalna sesja dermatoonkologiczna, w której eksperci z gdańskiej Kliniki Dermatologicznej przedstawili aktualne wytyczne dotyczące terapii ziarniniaka grzybiastego, mastocytozy oraz nowotworów skóry.

W spotkaniu wzięło udział ponad 200 lekarzy z całego kraju. Wśród 50 wykładowców znaleźli się zarówno profesorowie $\mathrm{z}$ wielu ośrodków akademickich w Polsce, jak i znakomici goście i przyjaciele z Anglii, Białorusi, Łotwy, Rosji i Ukrainy, dzięki którym 16. ADA zyskała wymiar międzynarodowy. Program konferencji obejmował 7 sesji naukowych, w tym sesję przypadków klinicznych oraz specjalną sesję niedzielną zorganizowaną z okazji XXVIII Światowego Dnia Chorego.

Uroczystego otwarcia Akademii dokonał przewodniczący Komitetu Organizacyjnego i Naukowego 16. ADA prof. Roman J. Nowicki, kierownik Kliniki Dermatologii, Wenerologii i Alergologii GUMed, który powitał przybyłych gości, przedstawicieli uczelni, władz Gdańska i Gdyni, wykładowców oraz wszystkich uczestników konferencji. Rektor Gdańskiego Uniwersytetu Medycznego prof. Marcin Gruchała przekazał gościom honorowym 16. ADA listy powitalne i drobne upominki (ryc. 2). Prezes Polskiego Towarzystwa Dermatologicznego prof. Lidia Rudnicka wręczyła prof. Uladzimirowi Adaskevitchowi, kierownikowi Kliniki Dermatowenerologii w Witebsku oraz prof. Dzmitrowi Khvorikowi, kierownikowi Kliniki Dermatowenerologii w Grodnie dyplomy członków Rady Naukowej „Przeglądu Dermatologicznego" - oficjalnego organu PTD (ryc. 3).

Sesję inauguracyjną obejmującą 7 wykładów rozpoczęła, podobnie jak w roku ubiegłym, prof. Rudnicka z Warszawy, która tym razem przedstawiła zmiany w obrębie skóry owłosionej głowy jako objaw chorób narządów wewnętrznych. Profesor Maciej Kaczmarski z Białegostoku omówił uwarunkowania przyczynowe ciężkiego przebiegu atopowego zapalenia skóry (AZS) w wieku rozwojowym. Zwrócił uwagę na konieczność dogłębnej diagnostyki alergologicznej tych chorych, która ma na celu ustale- 


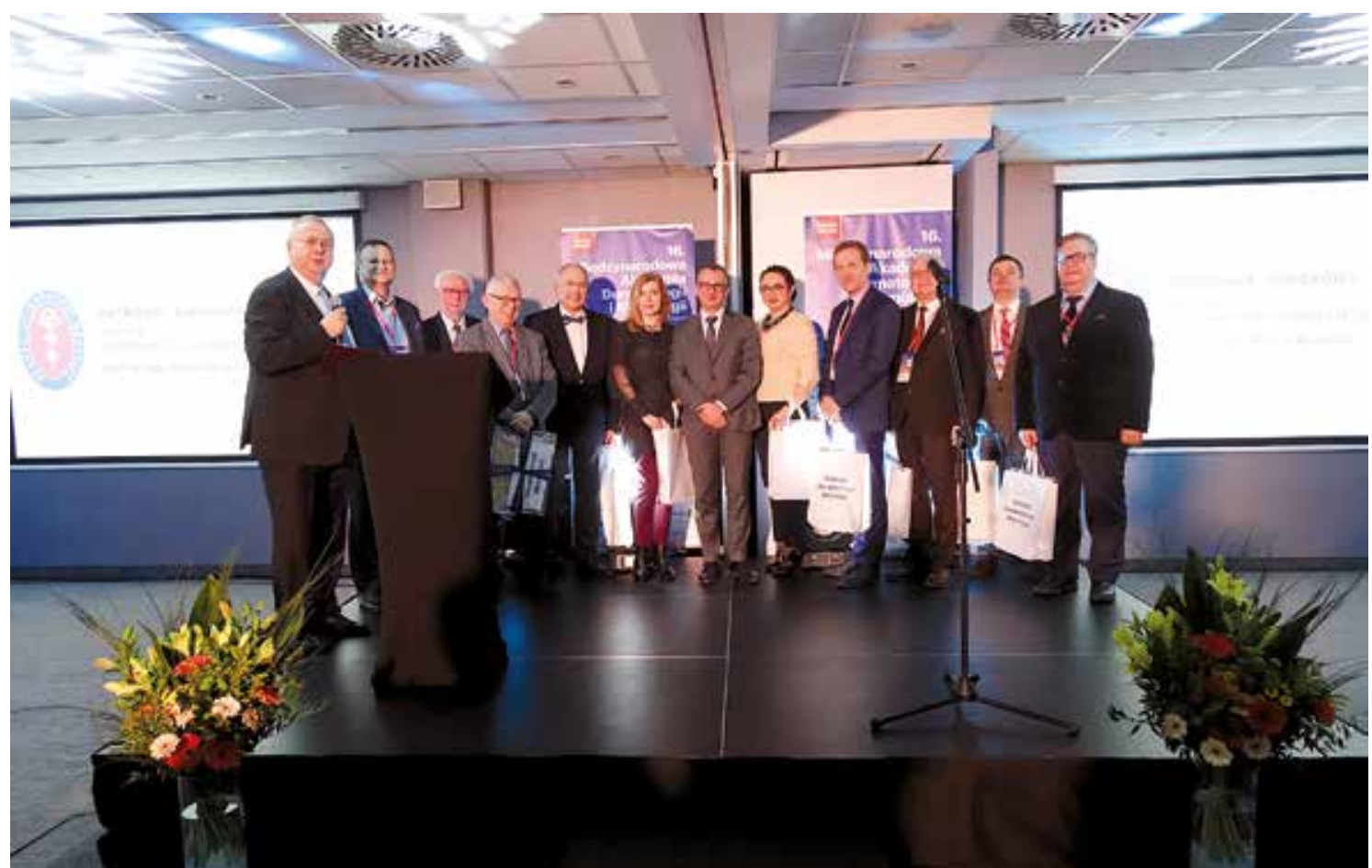

Rycina 2. Rektor GUMed prof. M. Gruchała z gośćmi honorowymi I6. ADA

nie wszystkich czynników istotnie wpływających na nasilenie choroby. Kontynuując tematykę AZS, prof. Nowicki przedstawił aktualne wytyczne dotyczące leczenia wyprysku atopowego w aspekcie interdyscyplinarnym. Specjalny gość konferencji, dr Clive Grattan z Londynu, wybitny ekspert i twórca wielu konsensusów dotyczących leczenia pokrzywki, zaprezentował nowe możliwości terapii tego schorzenia z zastosowaniem leków biologicznych (ryc. 4). Problemowi pokrzywki poświęcony był również wykład prof. Marcina Moniuszki (Białystok). Głównym przedmiotem prezentacji była ocena zasadności i efektywności podejmowania określonych interwencji diagnostycznych i terapeutycznych zorientowanych na szeroko rozumiane choroby wewnętrzne wykryte u pacjentów z przewlekłą pokrzywką. Z kolei przewodniczący Białoruskiego Towarzystwa Dermatologów i Kosmetologów prof. Adaskevitch z Witebska omówił problem trądziku różowatego w aspekcie kliniczno-epidemiologicznym i terapeutycznym, zwracając uwage na klasyczne podtypy choroby, jak również jej rzadkie odmiany. Na zakończenie sesji inauguracyjnej prof. Jerzy Kruszewski (Warszawa) podsumował 16 lat Akademii Dermatologii i Alergologii. W bardzo interesującym wykładzie wzbogaconym bogatą dokumentacją fotograficzną zostały przypomniane najważniejsze wydarzenia związane z długoletnią już historią konferencji. Profesor Kruszewski zwrócił uwage na interdyscyplinarny charakter tego sympozjum, pogratulował prof. Nowic-

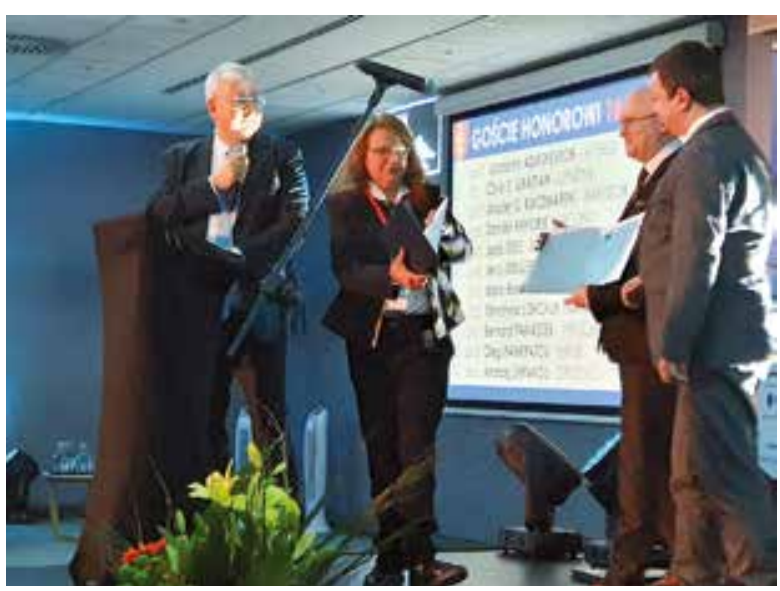

Rycina 3. Profesor L. Rudnicka wręcza nominacje nowym członkom Rady Naukowej „Przeglądu Dermatologicznego“

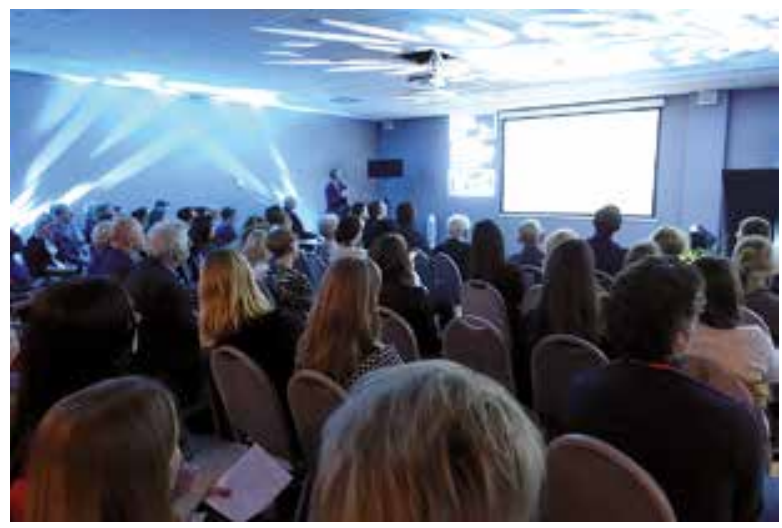

Rycina 4. Wykład inauguracyjny dr. Clive'a Grattana z Londynu 


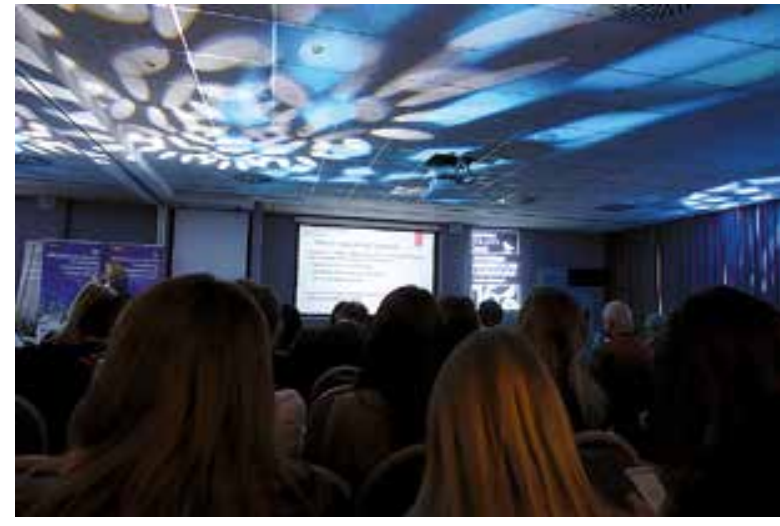

Rycina 5. Obesity and allergic diseases - prof. M. Kupfere z Rygi

kiemu dotychczasowego sukcesu oraz życzył, aby nie ustawał w kontynuowaniu tej ważnej inicjatywy.

Kolejny dzień konferencji był wypełniony od świtu do późnego wieczoru. Do tak intensywnego programu wszyscy uczestnicy Akademii zdążyli się już przyzwyczaić. O 6.55 rozpoczęła się sesja przypadków klinicznych, w której zademonstrowano 14 bardzo interesujących i zróżnicowanych przypadków. Pomimo wczesnej pory frekwencja była duża, a dyskusja bardzo żywa i pouczająca. Kolejna sesja "Dermatologia bez granic" obejmowała 14 wykładów, w tym prezentacje gości zagranicznych z Mińska, Rygi (ryc. 5) oraz Lwowa. Wśród wykładów polskich autorów duże zainteresowanie wzbudziła prezentacja prof. Bernarda Panaszka (Wrocław), który przedstawił interesujące dane na temat nowych funkcji immunoglobuliny E w pokrzywce przewlekłej i innych chorobach skóry. Ugruntowane znaczenie immunoglobuliny E (IgE) jako cząsteczki odpowiedzialnej za natychmiastową reakcję immunologiczną uległo w ostatnich latach istotnej modyfikacji, ponieważ zostały odkryte inne właściwości IgE. Te nowe funkcje IgE wpisują się w zjawiska autoimmunizacji występujące w klasycznych chorobach autoimmunologicznych oraz $\mathrm{w}$ procesy autoimmunologiczne widoczne w pokrzywce przewlekłej spontanicznej (PPS). W tym zakresie PPS z autoreaktywnymi IgG oraz IgE wydaje się mieć charakter choroby autoimmunologicznej albo odzwierciedlać kliniczną manifestację schorzenia $\mathrm{z}$ autoagresji, $\mathrm{w}$ którym autoantygeny reagujące z IgE mogą być czynnikami spustowymi aktywującymi mastocyty i bazofile. Profesor Wojciech Baran (Wrocław) omówił pieluszkowe zapalenie skóry (PZS), jedną z najczęstszych dermatoz wieku noworodkowego. Na podstawie bogatej dokumentacji fotograficznej wykładowca przedstawił najważniejsze zagadnienia dotyczące różnicowania i główne zasady leczenia PZS. Ogromną wartość praktyczną miał wykład prof. Małgorzaty Olszewskiej z Kliniki Dermatologicznej Warszawskiego Uniwersytetu Medycznego, w którym prelegentka omówiła kliniczne spektrum złuszczającego zapalenia dziąseł. W praktyce dermatologicznej częstą przyczyną tego objawu jest liszaj płaski oraz choroby pęcherzowe. $W$ kilku procentach przypadków zajęcie dziąseł jest jedynym objawem śluzówkowym pęcherzycy zwykłej. Złuszczające zapalenie dziąseł jest często wyzwaniem diagnostycznym dla dermatologa, szczególnie trudnym w przypadku izolowanego występowania tego objawu. Znajomość tych zmian śluzówkowych pozwala na wczesne rozpoznanie wielu jednostek chorobowych. W sesji „Alergologia bez granic" usłyszeliśmy 8 wykładów o bardzo różnej tematyce. Na wstępie sesji prof. Marta Chełmińska z Kliniki Alergologii GUMed przedstawiła problem alergii na penicylinę pod kątem możliwości diagnostycznych. Konsekwencją przeprowadzonej diagnostyki jest tzw. delabeling u ok. 75\% osób zgłaszających w wywiadzie objawy sugerujące alergię na penicylinę. Zanegowanie rozpoznania umożliwia zapewnienie optymalnej, racjonalnej antybiotykoterapii oraz rzeczywiste oszczędności w opiece zdrowotnej. Profesor Barbara Rogala (Katowice) w wykładzie „Immunoterapia alergenowa vs terapia biologiczna - co wybrać i kiedy" podjęła się trudnej próby ustalenia wskazań do każdej z tych metod terapeutycznych w schorzeniach atopowych. Immunoterapia indukuje tolerancję immunologiczną na alergeny, które są przyczyną choroby atopowej. Ten sposób leczenia oddziałuje immunosupresyjnie na ostrą fazę reakcji alergicznej i na rozwój przewlekłego zapalenia. W cięższych postaciach chorób $\mathrm{z}$ kręgu atopii reakcja zapalna toczy się w określony sposób autonomicznie, niezależnie od ekspozycji na alergen, co istotnie ogranicza stosowanie immunoterapii alergenowej i wskazuje na celowość terapii biologicznej, która nie jest swoista dla alergenu, ale koryguje określone ogniwa zaburzonych procesów immunoregulacji. Jak zwykle dużym zainteresowaniem cieszył się wykład prof. Radosława Śpiewaka z Krakowa (ryc. 6), który przedstawił zmiany w europejskich i polskich seriach diagnostycznych do testów płatkowych. W 2019 roku eksperci Europejskiego Towarzystwa Wyprysku Kontaktowego (ESCD), do których należy również prof. Śpiewak, opublikowali nowe rekomendacje dotyczące składu Europejskiej Serii Podstawowej, stanowiącej bazę dla serii narodowych na naszym kontynencie. Zalecenia te zostały uwzględnione $\mathrm{w}$ aktualnie przygotowywanych standardach Polskiego Towarzystwa Alergologicznego, stosownie do nich zmienił się także skład Polskiej Serii Podstawowej. W tej sesji mogliśmy jeszcze raz usłyszeć prof. Panaszka, który tym razem przedstawił fenotypy nadwrażliwości na niesteroidowe leki przeciwzapalne (NLPZ) w pokrzywce przewlekłej i możliwości uzyskania tolerancji tych leków. Podstawowa klasyfikacja reakcji niepożądanych na NLPZ obejmuje objawy związane z nietolerancją grupy, 
wynikające z nadwrażliwości krzyżowej spowodowanej hamowaniem cyklooksygenazy 1 (COX-1) oraz immunologicznymi reakcjami selektywnymi, z udziałem IgE i limfocytów T, zależnymi wybiórczo od jednego leku. Diagnostykę nadwrażliwości na NLPZ ograniczają różnorodne czynniki, m.in. brak wiarygodnych biomarkerów laboratoryjnych i testów skórnych. Nadal złotym standardem diagnostycznym jest doustny test prowokacyjny $z$ aspiryną. Jeszcze raz w tej sesji powrócił problem pokrzywki, tym razem w wykładzie prof. Macieja Kupczyka (Łódź), który przedstawił możliwości diagnostyczno-terapeutyczne tego bardzo trudnego problemu w codziennej praktyce dermatologa i alergologa. Zgodnie z obowiązującym konsensusem leczenia pokrzywki w przypadku braku optymalnej kontroli objawów choroby lekami przeciwhistaminowymi należy wdrożyć do terapii omalizumab - humanizowane przeciwciało monoklonalne anty-IgE. Lek ten spektakularnie redukuje nasilenie objawów choroby i poprawia jakość życia. Dostępność w Polsce terapii biologicznej w ramach programu terapeutycznego zdecydowanie poprawi kontrolę choroby u pacjentów z przewlekłą pokrzywką spontaniczną, niereagującą na leczenie standardowe.

Popołudniową sobotnią sesję poświęconą łuszczycy rozpoczął wykład dr. Bogusława Nedoszytko (GUMed) na temat epigenetyki tej przewlekłej, zapalnej choroby. Doktor habilitowana Agnieszka Owczarczyk-Saczonek (Olsztyn) w kolejnej prezentacji podjęła próbę odpowiedzi na pytanie: „Dlaczego wykwity łuszczycowe pojawiają się w tej samej lokalizacji?". Dwa kolejne wykłady poświęcone były ogólnoustrojowym manifestacjom choroby - pierwszy wygłosił prof. Khvorik (Grodno), drugi dr hab. Aneta Szczerkowska-Dobosz (GUMed), która omówiła łuszczycowe zapalenie stawów ze szczególnym akcentem na wczesne rozpoznanie tej zapalnej spondyloartopatii. Cztery kolejne wykłady dotyczyły różnych zagadnień związanych z leczeniem łuszczycy - od terapii łuszczycy dziecięcej (prof. Wojciech

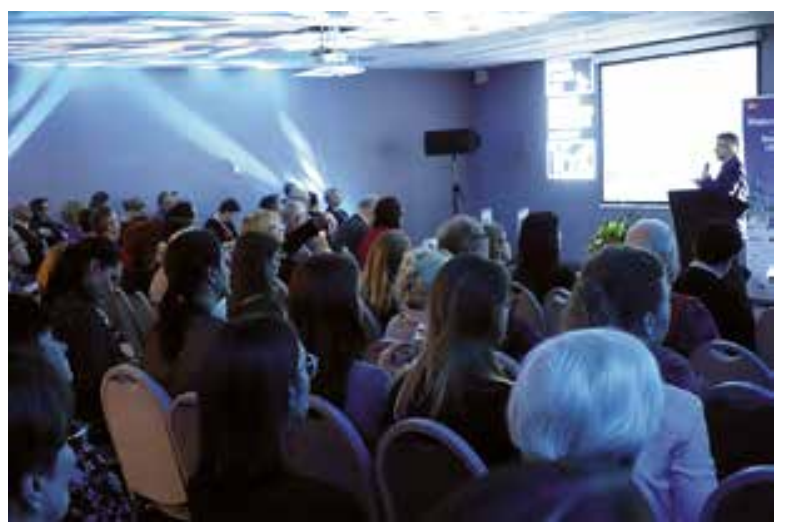

Rycina 6. Profesor R. Śpiewak z Krakowa
Baran - Wrocław) po leczenie biologiczne (dr hab. Aldona Pietrzak - Lublin, dr Aleksandra Wilkowska GUMed). Na zakończenie sesji prof. Adam Reich (Rzeszów) nakreślił w interesujący sposób perspektywy leczenia łuszczycy. W ostatnim dwudziestoleciu obserwowaliśmy najszybszy rozwój lecznictwa dermatologicznego, który został niewątpliwie zapoczątkowany przez wprowadzenie leków biologicznych do terapii łuszczycy. Aktualne badania kliniczne mają na celu rozszerzenie wskazań już zarejestrowanych leków na populację pediatryczną lub na pacjentów z rzadszymi odmianami łuszczycy. Opracowywane są także nowe formulacje poprawiające skuteczność dotychczasowych leków miejscowych.

Ostatnia sesja w sobotni wieczór, zatytułowana „Co nowego", była bardzo zróżnicowana tematycznie. Kilka wykładów poświęcono nowym możliwościom terapii schorzeń z kręgu alergii - atopowego zapalenia skóry, pokrzywki i obrzęku naczynioruchowego (prof. Jerzy Kruszewski - Warszawa, prof. Zenon Brzoza - Opole, dr Michał Adamczyk Lublin, dr Tomasz Matuszewski - Warszawa). W kolejnym wykładzie prof. Wioletta Barańska-Rybak (GUMed) przedstawiła aktualnie prowadzone badania kliniczne z nowymi lekami w terapii miejscowej trądziku oraz przypomniała najważniejsze rekomendacje American Academy of Dermatology dotyczące leczenia tej dermatozy. Doktor Zbigniew Swacha (Warszawa) omówił wskazania i nowe możliwości terapii fotodynamicznej (PDT), która znajduje coraz szersze zastosowanie $\mathrm{w}$ dermatologii. $\mathrm{W}$ ostatnich latach następuje znaczący postęp w tworzeniu nowych substancji fotouczulających, zmieniają się również źródła światła stosowane w PDT. Niezwykle ważny dla dermatologów wykład przedstawił prof. Zbigniew Zdrojewski (GUMed), który omówił rekomendacje dotyczące postępowania w toczniu rumieniowatym układowym (TRU) zaktualizowane przez EULAR w 2019 roku. Leczenie TRU wymaga zaangażowania wielodyscyplinarnych zespołów terapeutycznych. Terapia poszczególnych postaci choroby z zajęciem

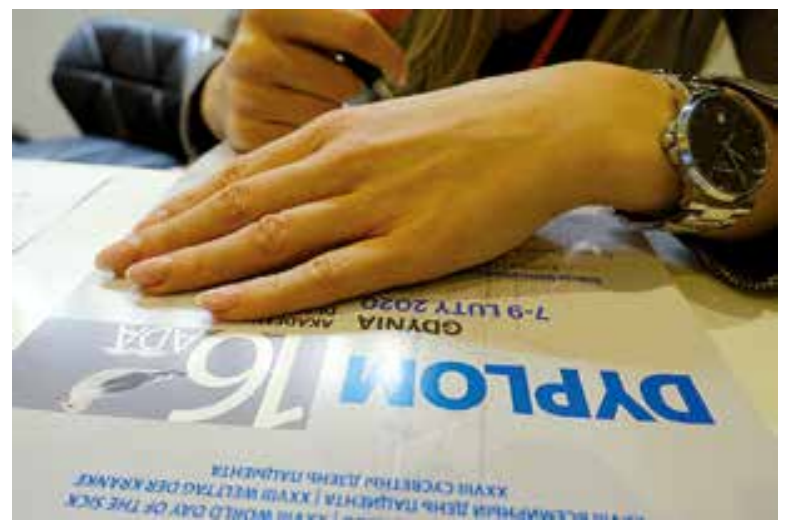

Rycina 7. Pamiątkowy dyplom 16. ADA 
narządów zagrażającym życiu obejmuje początkowy okres z bardzo intensywną immunosupresją (opanowanie aktywności choroby), a następnie długotrwały okres mniej intensywnego leczenia zmierzającego do konsolidacji i podtrzymania remisji oraz zapobiegania nawrotom. Celem leczenia TRU jest długotrwałe utrzymanie chorego przy życiu, zapobieganie uszkodzeniom narządowym oraz poprawa jakości życia.

W przerwach pomiędzy wykładami uczestnicy konferencji mogli odwiedzić stoiska wydawnictw oraz licznych firm farmaceutycznych i medycznych.

W niedzielę, 9 lutego 2020 roku organizatorzy i goście 16. ADA tradycyjnie obchodzili XXVIII Światowy Dzień Chorego podczas specjalnej interdyscyplinarnej sesji, w której szczególną uwagę poświęcono cierpieniu ludzi chorych oraz uniwersalnym metodom zachowania zdrowia.

Każdy uczestnik konferencji otrzymał 19 punktów edukacyjnych potwierdzonych pamiątkowym dyplomem (ryc. 7) i 150-stronicową książkę ze streszczeniami prezentacji.

Do udziału w kolejnej, 17. Akademii Dermatologii i Alergologii zapraszamy do Gdyni już za rok, w dniach 11-13 lutego 2021 roku (www.17ada.pl).

Elżbieta Grubska-Suchanek Roman J. Nowicki 